\title{
CLIL: Enhancing Engineering Research Article Reading Skills and Vocabulary Knowledge
}

\author{
Budsaba Kanoksilapatham ${ }^{1}$, Attapol Khamkhien ${ }^{2}$ \\ Silpakorn University, Thailand ${ }^{1}$ \\ Kasetsart University, Thailand ${ }^{2}$
}

\begin{abstract}
The increasing global and local demands to improve citizen's English proficiency has augmented the significance of English education across the entire paradigm. In fact, in Thailand, improving Thai university graduates' English has been one of the burgeoning challenges. Given the significance of academic research articles in the field of engineering and the paramount importance of English, this study focuses on Content Language Integrated Learning (CLIL) implementation in a research methodology course offered to engineering students in a university in Thailand. The objectives of the current study are to estimate the CLIL impact in enhancing the engineering students' expertise in reading English research articles and enlarging the students' academic vocabulary repertoire. Throughout CLIL, the language university teachers were in close collaboration with the non-language engineering teachers, including designing the course materials focusing on engineering research articles, developing language tasks and activities, and constructing testing instruments. To compensate for the Thai learners' relatively limited exposure to the English language, supporting systems like online English lessons on grammar and academic vocabulary were provided. Two sets of similar pre-tests and post-tests in research article reading and vocabulary were administered in Week 1 and Week 8, respectively. The analysis of the test scores congruently yielded positive and significantly enhanced output in the both the content subject and the English language. This study demonstrates that, to achieve full optimization of the potential benefits of CLIL, scaffolding needs to be supplemented to accommodate individual learning contexts.
\end{abstract}

Keywords: CLIL, engineering, research article reading, Thailand, vocabulary 


\section{Introduction}

Recently, the increasing global and local demands to improve citizen's English proficiency has augmented the significance of English education across the entire paradigm. In fact, in Thailand, improving Thai university graduates' English has been one of the burgeoning challenges. Meanwhile, Content Language Integrated Learning (CLIL) has been adopted worldwide since 1994 as an approach that promotes more motivated and sustained learning attainment (Marsh, 2000). Methodologically, CLIL is a dual-focused approach emphasizing the content of the subject and also the language. To sum up the CLIL features, Coyle, Hood, \& Marsh $(2010,1)$ maintain that CLIL is "a dual-focused educational approach in which an additional language is used for the learning and teaching of both content and language". Dalton-Puffer $(2007,2011)$ even further highlights that the focus of CLIL teaching is the content subject, not the language. Previous empirical research studies on CLIL have demonstrated the positive impacts of this teaching approach in teaching the content subjects of diverse disciplines, in a number of educational establishments, in different levels of education, and in a variety of academic contexts (e.g., Coyle, Hood, \& Marsh, 2010; Dale \& Tanner, 2012; Dalton-Puffer \& Smit, 2007; Fan \& Lo, 2016; Lo, 2014; Lo et al., 2018; Lorenzo et al., 2010; Smala, 2012; Nikula et al., 2013; Nowak, 2011). Based on these studies, it can be concluded that this teaching approach has been successful in encouraging students to learn the content and the target language at the same time.

In Thailand, the English language has continually enjoyed wide recognition as one of the vital tools to develop the country. Thus, English education has received substantial attention from all sectors. As a consequence, a number of teaching approaches were introduced into the system with the primary goal to enhance Thai learners' English. Some examples of the attempts in this regard include the provision of English Programs (EP) and later Mini-English Programs (MEP) in a large number of Thai schools. At present, the number of public and private schools offering EPs and MEPs is mushrooming and flourishing, suggesting the overwhelming demand for English language education.

At this juncture, a scrutiny of CLIL as one of the teaching approaches recognized to be successful is needed. In the English as a Foreign Language (EFL) context, as is the case when teaching English in Thailand, a number of observations need to be made. For example, the English proficiency of Thai learners has been found to be inadequate. In fact, the success of English education across the entire paradigm in Thailand is substandard, be it assessed by national or international examinations (e.g., Kanoksilapatham, 2016; Kanoksilapatham \& Channuan, 2018; Kanoksilapatham \& Suranakkharin, 2018). In relevance to CLIL in which the non-language teacher has to take a double role as a resource person in the classroom, not only as a content teacher but also a language teacher, CLIL implementation in elementary or even secondary schools in Thailand might be too daunting for not only the students but also the non-language teachers. This means that the students need to be proficient in English at a certain level to be able to cope with the instruction delivered by the content or non-language teacher. Not only that, the teachers must possess a certain level of English proficiency to be able to deliver the CLIL instruction, in addition to having the level of confidence to do so. Taking these constraints into consideration, this study aims to focus on higher education primarily due to the fact that higher education teachers are more likely to have a higher level of English expertise to handle and accommodate the demands of CLIL implementation. However, to ensure the success of CLIL implementation in Thailand, CLIL implementation needs to be accompanied by a number of supporting systems, including careful planning and 
collaboration between the language and non-language teachers and the meticulous execution of CLIL.

This study highlights CLIL implementation in an EFL context, in a public university setting to enhance both content subject literacy and English literacy. The content subject literacy here refers to engineering research article reading skills; whereas the English literacy refers to English academic vocabulary. The justification for focusing on the academic discourse of research articles is that in order to graduate, these engineering students are required to conduct research and write a research report in English. In addition, the ability to produce academic texts in English has become a necessary and an essential skill for university students in all fields of study. To prepare the engineering students for that direction, the engineering curriculum offers a three-course program on "research methodology," the first of which is offered in the second semester of the academic year. The CLIL study presented here is the first of the series, emphasizing the academic reading skills of research articles.

\section{The study}

This research presents a study on CLIL in an engineering course of research methodology, specifically focusing on engineering research article reading at a public university in Thailand.

\section{Objectives}

The objectives of this study are twofold. That is, after the eight-week CLIL implementation, it aims to investigate the role of CLIL implementation to engineering undergraduate students, in enhancing their reading skills of research articles in the field of engineering, and enlarging their repertoire of the vocabulary associated with academic discourse.

\section{Setting and participants}

The context of this study is a public higher education establishment in the central region of Thailand. Specifically, the study was contextualized in the Faculty of Engineering. According to the curriculum, the undergraduate students in this program at this university are required to enrol in three consecutive courses focusing on research methodology. The first course of the three-course series is offered in the second semester of each academic year - the time when this study was conducted. A total number of 135 undergraduate students in mechanical engineering are participants of this study. The first half of the course (the first eight weeks) was conducted by five engineering teachers, specializing in different areas of mechanical engineering. All of them completed their doctoral degree in Thailand. However, they have been actively involved in academic activities conducted in English including oral presentations and academic writing. The content of the first half of the semester includes introducing the students to some general theoretical issues of research methodology and exposing them to a variety of research articles published in English on a variety of topics. As is common practice in this program, in all courses, and in the first eight weeks, the language of instruction was Thai.

It is in the second half of the course (the last eight weeks) that CLIL was launched. In this second half, the same five mechanical engineering teachers and the two language teachers 
worked closely together a few weeks before CLIL was implemented and for the entire CLIL period of eight weeks. The language of CLIL instruction was in English only.

\section{Materials for CLIL instruction}

In this section, CLIL instructional materials or instruments consist of two major parts: five sets of instructional materials for the entire period of eight weeks and two sets of tests assessing the learners' content and language literacies. A description of how these materials were devised follows.

According to the typical protocol of CLIL instruction, the materials employed for the instruction result from close collaboration between the language and non-language teachers. In this case, multiple meetings between the non-language and language teachers were held to discuss the scope and scale of the instructional materials that are directly generated from the course. After the scope was specified, CLIL material construction began. In this regard, Swales' genre analysis (2004) was selected to be relevant and address the goals of this study. That is, based on genre analysis, particularly of research articles, individual sections of research articles follow a typical organizational structure and can be recognized by a cluster of co-occurring linguistic features. To elaborate, for example, the Introduction section of a research article is to contextualize the study being presented using a number of strategies, including the centrality of the topic, topic generalization, and previous studies review. Given this research methodology course is the first one in the three-course series, it is imperative that the engineering students are able to recognize the principal function of each research article section while reading. In short, Swales' genre analysis (2004) provides a basis for designing and developing five sets of CLIL materials corresponding to the major components or sections of research articles in the following order: Introduction, Methods, Results, Discussion, and Abstract.

To accomplish the stage of developing instructional materials for CLIL, the five nonlanguage teachers were requested to nominate two research articles of their expertise so that the language teachers could to generate the CLIL instructional materials. The selection criteria included the length of the article, the sections of the article, and the language used. After the selection of ten research articles nominated, Swales' genre analysis (2004) was subsequently conducted to identify a number of sentences that clearly elucidate the functions of individual research article sections to be used in CLIL. At this juncture, the CLIL materials consist of ten intact original research articles for the students to read. Then, each lesson focusing on individual research article sections is accompanied by a set of authentic sentences drawn from the ten selected articles that clearly highlight the function of individual sections of the research article genre.

To compensate for relatively limited exposure to the English language particularly in the Thai EFL context, and to make sure that the Thai EFL learners fully benefit from the CLIL instruction, based on the organizational structure derived from genre analysis and the sentences selected to highlight the functions of individual sections, a number of linguistic features (including grammatical features, lexical features, and linguistic constructions) were highlighted. Then, a variety of language tasks, activities, and exercises were developed to reinforce the meaningful use of those features.

To address the objectives of the study, two sets of identical pretests and posttests were constructed to assess the learners' content knowledge and English knowledge. As defined earlier, the content literacy here refers to the skills of reading research articles. This content 
literacy test consists of 40 statements taken directly from the articles used in class. The students were required to read and identify the research article section (Introduction, Methods, Results, and Discussion) to which the statements belong. In short, for this part, ten statements represent each section, yielding 40 statements from the four sections as exemplified in Figure 1. All of the 40 test items in this part were validated by the five non-language teachers for content and appropriateness. As shown in Fig. 1, the answers to statement numbers 1 to 4 are Methods, Results, Discussion, and Introduction.

Figure 1: Research Article Reading Test

1. This study used questionnaires and survey forms as the research instruments.

2. From the analysis, the biomass ratio on the water resistance had no effect.

3. There were several study limitations, including the lack of control of the characteristics of the substances.

4. Forest residues represent a major fuel source for potential bioenergy projects in many countries.

To address the second objective of enhancing the learners' English literacy, the English literacy was subcategorized as the academic vocabulary repertoire. Similarly, a set of 40 words taken from Coxhead's 2000 academic word list (the first five subgroups) was used as the target of the test. Based on these 40 words, 40 statements were generated. For each statement, four alternatives were given for the students to select the best option to complete the statement. Similar to the content literacy test, these 40 items were validated by the five non-language teachers. One of the vocabulary test items is shown in Fig. 2.

Figure 2: Research Article Reading Test

1. Wind-surfers and kayaks are for rent at the beach.
a. available
b. individual
c. significant
d. economic

2. The students did an exercise in which they had to the new vocabulary according to its part of speech.
a. institute
b. transfer
c. categorize
d. regulate

3. Alcohol was a major in car accidents which claimed many lives last year.
a. formula
b. function
c. factor
d. finance

4. The planet Mars has a surface which is somewhat to that of our moon.
a. specific
b. similar
c. legal
d. evident

5. Though it could take months to ___ the data, the results will be useful to our project.
a. establish
b. constitute
c. analyze
d. legislate

\section{CLIL implementation}

As mentioned, CLIL implementation lasted for a total of eight sessions, one session a week. The first and last sessions (Week 1 and Week 8) were reserved for the pre-tests and post-tests of the content and English literacies. Throughout the 8-week implementation period, the language teachers worked in close collaboration with the non-language teachers, but behind the scenes. That is, before each session of two class periods (50 minutes each), a 
training session was conducted by a language teacher to the five non-language teachers to ensure that the language part was clear to them, and that they clearly understood how to conduct the language tasks, activities, and exercises. Weeks 2 and 3 focused on the Introduction section, whereas Weeks 4, 5, 6, and 7 on the sections of Methods, Results, Discussion, and Abstract. The five non-language teachers decided among themselves which person would conduct the class; they were requested to strictly use only the English language as a medium of instruction. To keep a balance between the focus on the content and the language, the five non-language teachers were encouraged to spend the first 50 minutes on the instruction of content, and the other 50 minutes on language-related activities. Finally, to estimate the effectiveness of the CLIL implementation, both the content knowledge and the language knowledge were assessed by using the two sets of post-tests in Week 8 .

\section{Data collection and analysis}

The pre-test and post-tests scores of the content and English vocabulary collected in Week 1 and Week 8, respectively serve as the data of this study. To examine the impact of CLIL implementation on these engineering university students, descriptive statistics and t-test score analysis were conducted to observe any knowledge gain over the implementation.

\section{Results}

The participants of this study were 135 engineering students enrolled in research methodology. Based on the pre-test and post-test score analysis on the content literacy (identifying the research article sections pertaining to individual statements), the following table shows the data obtained.

Table 1: Descriptive statistics and t-test on the content subject $(n=135)$

\begin{tabular}{|l|c|c|c|}
\hline & Pre-test & Post-test & Sig. \\
\hline Mean & 18.39 & 19.76 & .003 \\
\hline Standard deviation & 4.61 & 6.22 & \\
\hline Standard error mean & 0.40 & 0.54 & \\
\hline
\end{tabular}

As shown in the above table, the analysis of the content pre-test scores revealed that, of all of 135 participants and a total score of 40 points, the mean score for the pre-test was 18.39 , indicating that the participants were somewhat familiar with the four research article sections in engineering. The post-test score analysis, after eight weeks of CLIL instruction, showed that the mean score was slightly higher at 19.76. To determine whether the comparison of the pre-test and post test scores yield significant difference, $t$-test analysis conducted on the both the pre-test and post-test scores demonstrates that the knowledge gain was significant at 0.003 .

Now let us consider the scores of the English vocabulary associated with the research articles. The analysis of the pre-test and post test scores of this part is shown in Table 2. 


\begin{tabular}{|l|c|c|c|}
\hline & Pre-test & post-test & Sig. \\
\hline Mean & 15.83 & 16.74 & .006 \\
\hline Standard deviation & 5.94 & 5.52 & \\
\hline Standard error mean & 0.51 & 0.48 & \\
\hline
\end{tabular}

As presented in Table 2, the analysis of the pre-test vocabulary scores revealed that, of all of 135 participants and a total score of 40 points, the mean score for the pre-test was 15.83, indicating that the participants were not that familiar with the vocabulary associated with research articles. The post-test result analysis after eight weeks of CLIL instruction showed that the mean score was slightly higher at 16.74. The comparison of the pre-test and post test scores by using t-test analysis demonstrates that the vocabulary knowledge gain was significant at 0.006 .

\section{Discussion}

This study provides additional insights into the implementation of CLIL in an EFL context in Thailand. It aims to examine whether CLIL in an EFL context could promote the learners' content subject literacy. As known, Swales' genre analysis (2004) is useful for analysing rhetorical structure, while sharpening the students' ability to observe how academic language works in context. In this paper, content subject literacy represents the ability to identify the sections to which the statements belong, a basic foundation for better understanding how research articles are constructed, which potentially leads to the ability to create academic texts conforming to accepted conventions. Based on the quantitative results, the learners demonstrate an enhanced ability in performing this task.

Vocabulary knowledge is prerequisite of communication; therefore, the second aim of this study is to estimate the learners' knowledge of English vocabulary items associated with the research article discourse. The quantitative analysis congruently reveals the positive impact of CLIL in enhancing vocabulary repertoire. Based on these two findings, it can be claimed that CLIL does exert a positive impact on improving the content subject and English literacies.

Pedagogical implications from this study are multiple. Initially, this study indicates that CLIL represents an effective approach that both language and non-language teachers can collaborate on to fruitfully focus on both the content subject and the language. The positive impacts are not only on the learners but also on the teachers involved in CLIL, particularly the non-language teachers. That is, in CLIL, even though the non-language teachers are expert and professional in their discipline, they might feel somewhat reluctant to take on the responsibility of language teaching (Koopman \& de Graaff, 2014). However, once embarking upon CLIL instruction, they are compelled to be knowledgeable of pedagogical strategies and techniques to a certain extent. In this study, the techniques and strategies were acquired by these five non-language teachers through multiple training sessions, both before and during the CLIL implementation phase.

In addition to being aware of pedagogical strategies and techniques, the five non-language teachers can become more competent in delivering CLIL lessons in English. In other words, CLIL provides a channel for non-language teachers to develop their English competence. Initially, the five non-language teachers were hesitant when asked to participate in this CLIL project. This is in line with the study by Lorenzo, Casal, and Moore (2010) that reveals that 
CLIL teachers lack confidence, as they have an insufficient level of language skills to implement CLIL. As CLIL teachers are subject content experts but rarely have language qualifications, helping CLIL teachers to improve their English proficiency and CLIL teaching concepts is necessary (Nikula et al., 2013; Perez Canado, 2016; Wolff, 2012). In this study, after they were coerced into participating in this project by the researchers and finally agreed, they managed to handle a CLIL class in English for an extended period of time. Therefore, CLIL can help contribute to enhanced English competence. Along with the competence, the non-language teachers are likely to build up their confidence in using English as a medium of instruction and for classroom interaction.

All of the benefits mentioned, including competence and confidence, would not have been possible without multiple training and coaching sessions. In fact, the training and coaching sessions are crucial in CLIL, particularly in the Thai context. According to Lo (2014) and Tan (2011), the content subject teachers are likely to feel awkward when planning and delivering CLIL lessons in English. Therefore, systematic integration of content and language plays a key role in determining the success of CLIL (Davison \& Williams, 2011). As practiced in this study, the language and the non-language teachers systematically collaborate from the very beginning to make sure that the non-language teachers clearly understand the CLIL principles, and CLIL implementation was properly conducted, incorporating language teaching and content subject construction. As described in the previous section, the non-language teachers and the language teachers closely collaborated to make sure that CLIL was a success, including the syllabus design, material development, test construction, task, activities, and exercise creation. In this regard, the non-language teachers became aware of language teaching pedagogy and its impact in turning a regular class into a more interactive and lively class.

At this juncture, it can be said that CLIL allows the non-language teachers' professional development to take place right in the classroom. It is generally assumed that teachers need to constantly participate in professional development by attending workshops and conferences. However, this assumption might need to be somewhat revised. As shown in this study, the non-language teachers implicitly underwent, and actively participated in, professional development, though not in an engineering field, right in their own classrooms.

The findings of this study provide a number of pedagogical implications useful for further developing more rigorous CLIL implementation. For example, large-scale research to examine the non-language teachers' challenges in teaching content subjects through the lens of CLIL will contribute to a better understanding of how CLIL works. Given the limited scale and scope of the study, a broader study integrating a number of academic disciplines and a full course of CLIL instruction will definitely allow us to observe the learners' and the teachers' attitudes towards the CLIL instruction. Additionally, classroom observation provides valuable insights into examining the extent that the non-language teachers use English in CLIL, and in what ways, so that the language teachers can address these issues for further collaboration. Finally, for an advanced CLIL class, the tests executed can be more challenging, such as requiring the learners to produce research articles in engineering, following the appropriate organizational structure, and using the right grammatical features and vocabulary items. 


\section{Conclusion}

This article reports the collaboration between the language teachers and the five engineering teachers in a CLIL class that took place at a public university in Thailand. Prior to and during CLIL instruction, multiple training and coaching sessions were systematically conducted by the language teachers to the non-language teachers to equip the content subject teachers to deliver CLIL instruction. Similar pre-tests and post-tests on engineering research articles and vocabulary revealed that the learners substantially improved both bodies of knowledge. This study demonstrates that CLIL is not only beneficial to the learners but also the content subject teachers. That is, the teachers became more competent and confident, leading to sustainable professional development, particularly in English, while being engaged in teaching a content subject course.

\section{Acknowledgment}

This paper is an output of the research project supported by Thailand Research Fund (Grant No. RDH610030).

\section{References}

Coxhead, A. (2000). Selecting vocabulary: Academic word list. Available: http://www.uefap.com/vocab/select/awl.htm

Coyle, D., Hood, P., \& Marsh, D. (2010). CLIL: Content and language integrated learning. Cambridge, UK: Cambridge University Press.

Dale, L. and Tanner, R. (2012). CLIL activities: A resource for subject and language teachers. Cambridge, UK: Cambridge University Press.

Dalton-Puffer, C. (2007). "Outcomes and processes in CLIL: Current research from Europe," In W. Delanoy and L. Volkmann (eds.), Future perspectives for English language teaching (pp. 139-157). Heidelberg: Carl Winter.

Dalton-Puffer, C. (2011). "Content-and-language integrated learning: From practice to principles?” Annual Review of Applied Linguistics, vol. 31, pp. 182-204.

Dalton-Puffer, C. and Smit, U. (2007). Empirical perspectives on CLIL classroom discourse. Frankfurt am Main: Peter Lang.

Davison, C. and Williams, A. (2011). "Integrating language and content: Unresolved issues," in B. Mohan, C. Leung and C. Davison (eds.), English as a second language in the mainstream (pp. 51-70). Harlow, UK: Pearson.

Fan, C. C. and Lo, Y. Y. (2016). "Interdisciplinary collaboration to promote L2 Science literacy in Hong Kong," In A. Tajino T Stewart and D. Dalsky (eds.) Team teaching and team learning in the Language classroom: Collaboration for innovation in ELT (pp. 94112). London and New York: Routledge.

Kanoksilapatham, B. (2016). "Promoting global English while forging young northeastern Thai learners' identity," 3L: The Southeast Asian Journal of English Language Studies, vol. 22, pp. 127-140. 
Kanoksilapatham, B. and Channuan, P. (2018). "EFL learners' and teachers' positive attitudes towards local community-based instruction." Indonesian Journal of Applied Linguistics, vol. 7, pp. 504-515.

Kanoksilapatham, B. and Suranakkharin, T. (2018). "Celebrating local, going global: Use of northern Thainess-based English lessons," Asia TEFL, vol. 15, pp. 292-309.

Koopman, G. J. and de Graaff, R. (2014). "Exploring content teachers' knowledge of language pedagogy: A report on a small-scale research project in a Dutch CLH context," Language Learning Journal, vol. 42, pp. 123-136.

Lo, Y.Y. (2014). "Collaboration between L2 and content subject teachers in CBI: Contrasting beliefs and attitudes," RELC Journal, vol. 42, pp. 181-196.

Lorenzo, F., Casal, S. and Moore, P. (2010). "The Effects of content and language integrated learning in European education: Key findings from the Andalusian Bilingual Sections Evaluation Project," Applied Linguistics, vol. 31, pp. 418-442.

Marsh, D. (2000). CLIL: "An interview with Professor David Marsh," In Journal of Education and Development, vol. 29. Available: http://ihjournal.com/content-andlanguage-integrated-learning

Nikula, T., Dalton-Puffer, C. and Llinares, A. (2013). "CLIL classroom discourse,” Journal of Immersion and Content-Based Language Education, vol. 1, pp. 70-100.

Nowak, S. (2011). "The need for content and language integrated learning (CLIL) development," Paper presented at The $4^{\text {th }}$ International ALTE Conference: Impact of Language Frameworks on Assessment, Learning, and Teaching: Policies, Procedures, and Challenges, Jagiellonian University, Krakow, Poland.

Pérez Cañado, M. L. (2016). "Are teachers ready for CLIL? Evidence from a European study," European Journal of Teacher Education, vol. 39, pp. 202-221.

Smala, S. (2012). "CLIL programmes in Australia: Multilingual schooling contexts," The European Journal of Applied Linguistics and TEFL, vol. 1, pp. 171-130.

Swales, J. (2004). Research genres: Explorations and applications. Cambridge: Cambridge University Press.

Tan, M. (2011). "Mathematics and science teachers' beliefs and practices regarding the teaching of language in content learning," Language Teaching Research, vol. 15, pp. 325342.

Wolff, D. (2012). "The European framework for CLIL teacher education," Synergies Italie, vol. 8, pp. 105-116. 